\title{
Commentary: A tale of two valves
}

\author{
Jay K. Bhama, MD
}

\footnotetext{
From the Department of Cardiothoracic Surgery, Baptist Heart Failure and Transplant Institute, Baptist Health Medical Center, Little Rock, Ark.

Disclosures: Author has nothing to disclose with regard to commercial support.

Received for publication May 14, 2019; accepted for publication May 14, 2019; available ahead of print June 27, 2019.

Address for reprints: Jay K. Bhama, MD, Department of Cardiothoracic Surgery \& Heart Failure and Transplant Institute, Baptist Health Medical Center, 9601 Baptist Health Dr, Suite 990, Little Rock, AR 72205 (E-mail: jkbhama@me.com).

J Thorac Cardiovasc Surg 2020;159:908-9

$0022-5223 / \$ 36.00$

Copyright (c) 2019 by The American Association for Thoracic Surgery

https://doi.org/10.1016/j.jtcvs.2019.05.040
}

\begin{abstract}
It was the best of times, it was the worst of times, it was the age of wisdom, it was the age of foolishness, it was the epoch of belief, it was the epoch of incredulity, it was the season of Light, it was the season of Darkness, it was the spring of hope, it was the winter of despair, we had everything before us, we had nothing before us, we were all going direct to Heaven, we were all going direct the other way-in short, the period was so far like the present period, that some of its noisiest authorities insisted on its being received, for good or for evil, in the superlative degree of comparison only.
\end{abstract}

\section{-Charles Dickens, A Tale of Two Cities:} A Story of the French Revolution, 1859

In his opening paragraph of the literary classic, A Tale of Two Cities, ${ }^{1}$ Charles Dickens tells a story of contrasts and comparisons between two neighboring countries during the French Revolution. The opening clauses of this lengthy anaphora, "It was the best of times, it was the worst of times" form a phrase that is now often used to describe or compare paradoxic elements of a situation to predict a revolution or a sudden transformation. ${ }^{1}$

In this issue of the Journal, Tang and colleagues ${ }^{2}$ provide a unique perspective on the impact of mitral valve regurgitation (MR) and tricuspid valve regurgitation (TR) on the incidence of right ventricular dysfunction (RVD) after left ventricular assist device (LVAD) implantation. With data derived from a retrospective evaluation of prospectively collected data on 159 patients with severe preoperative MR, Tang and colleagues ${ }^{2}$ used a cluster analysis to identify 3 subgroups according to post-LVAD echocardiographic criteria: LVAD-unresponsive RVD without significant MR or TR (group 1), LVAD-unresponsive RVD with significant MR and TR (group 2), and LVAD-responsive RVD with significant MR but mild TR (group 3). Survival in group 2 was the worst $(17.6 \%$ at 5 years), and regression analysis demonstrated that greater MR severity after LVAD was

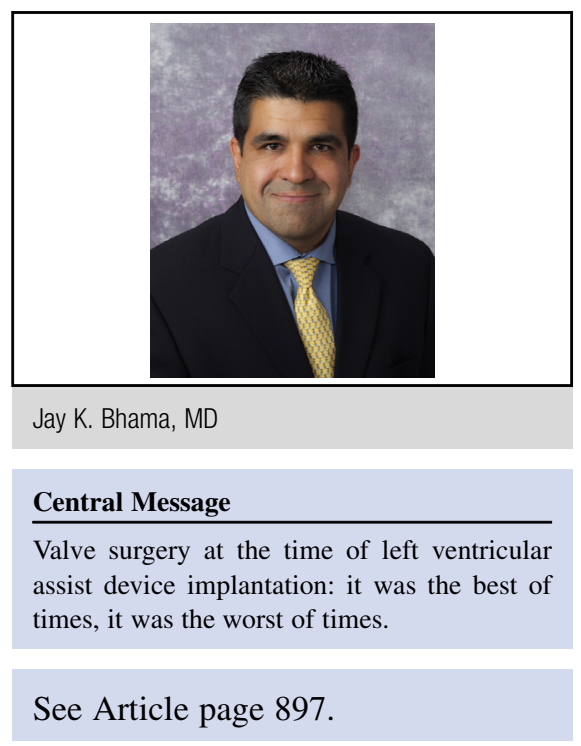

associated with RVD and need for temporary right ventricular assist device therapy. MR severity also correlated with TR severity. Tang and colleagues ${ }^{2}$ aptly conclude that patients with preoperative moderate to severe MR and TR coupled with moderate to severe RVD may benefit the most from mitral and tricuspid valve interventions.

The investigators from University of Michigan ${ }^{2}$ are to be commended for their efforts to elucidate the impact of MR and TR mitigation on RVD after LVAD therapy. As the pendulum continues to swing on this highly controversial question regarding the need for and value of correcting MR and TR at the time of LVAD placement, the study by Tang and colleagues ${ }^{2}$ is timely and provides a unique perspective by studying postoperative outcomes groups divided according to echocardiographic parameters. The data provided, although not without the limitations typical of a retrospective single-institution study, are provocative and yet in contradiction to numerous studies that have demonstrated minimal to no value for concomitant mitral or tricuspid valve surgery at the time of LVAD implantation. This study is particularly thought provoking when one considers that consensus guidelines from the International Society of Heart and Lung Transplantation actually warn against contemporaneous mitral valve repair at the time of LVAD placement as being of no value or actually being harmful. ${ }^{3}$ Despite this fact, interest in this topic remains high, and there seems to be a resurgence of interest, especially in mitral valve repair, largely because of a suspected positive effect on hospital readmission and improved quality of life. ${ }^{4}$ 
As aptly pointed out by Tang and colleagues, ${ }^{2}$ numerous studies on this topic seem to point us away from adopting an aggressive approach to mitral and tricuspid valve surgery at the time of LVAD implantation. And yet, the data presented here, along with growing interest in performing simultaneous mitral and tricuspid valve surgery, seem to suggest unwillingness on the part of surgeons simply to ignore such valve insufficiency. So it seems clear that in this "Tale of Two Valves," as demonstrated by Tang and colleagues, ${ }^{2}$ it really is the best of times and the worst of times!

\section{References}

1. Dickens C. A Tale of Two Cities. New York: Vintage Books; 1990.

2. Tang PC, Haft JW, Romano MA, Bitar A, Hasan R, Palardy M, et al. Right ventricular function and residual mitral regurgitation after left ventricular assist device implantation determines the incidence of right heart failure. J Thorac Cardiovasc Surg. 2020;159:897-905.e4

3. Feldman D, Pamboukian SV, Teuteberg JJ, Birks E, Lietz K, Moore SA, et al; International Society for Heart and Lung Transplantation. The 2013 International Society for Heart and Lung Transplantation guidelines for mechanical circulatory support: executive summary. J Heart Lung Transplant. 2013;32:157-87.

4. Robertson JO, Naftel DC, Myers SL, Tedford RJ, Joseph SM, Kirklin JK, et al. Concomitant mitral valve procedures in patients undergoing implantation of continuous-flow left ventricular assist devices: an INTERMACS database analysis. J Heart Lung Transplant. 2018;37:79-88. 